\title{
Discussion: Physical capabilities of reservoir panel engineers
}

Andy Hughes BSC, PhD, CEng, DMS, FICE, FCIWEM Director, Atkins, Epsom, UK
Owen P. Williams BSC(Eng), CEng, MICE, ACGI

Supervising Engineer, Astec Engineering Services Ltd, Llys-yr-Onnen, UK

\section{Contribution by Owen P. Williams}

I comment additionally as follows.

(a) As engineers are aware, confined spaces (CSs) have a legal definition and specific regulatory obligations apply to enable their safe access. However, undefined, unregulated and unsafe restricted spaces also abound among our dams and reservoirs, and I consider that the same capabilities are required for most of these. Indeed, for safe access and inspection, they are probably best managed in the same way as CSs are. My comments on CSs apply equally to restricted spaces.

(b) Where access to CSs is necessary for reservoirs owned and operated by large undertakers, each client will have the necessary equipment: air-quality monitors, harnesses, tripods, portable lighting and so on as well as in-house provisions for their essential testing, certification, maintenance and storage. This is an expensive service probably beyond the means of the sole practitioner panel engineer.

(c) What should be done at reservoirs where the undertaker also has no specialist equipment? Options include

(i) the client or his engineer, as agreed, hires a specialist contractor with suitable site-specific personal access equipment

(ii) the space is only entered by a remote-controlled camera operated and monitored from outside; this has the advantage of continuous recording for later assessment, but has limitations as well, especially around and under the pipework, valves, beams and floors

(iii) the engineer inspects as far as safely practicable, noting clearly (and reporting accurately) spaces not accessed or only partly accessed or indirectly observed - but is this an adequate inspection, especially for $\mathrm{S} 10$ ?

(iv) the engineer declines the appointment

but are options (ii), (iii) and (iv) sufficient and acceptable?

(d) I was once on site as SupEng shortly after the client had reassessed confined and restricted spaces and declared the draw-off tower as a prohibited area for all, including those who were CS trained. I considered that this, of itself, warranted an S12(3) recommendation for an S10 inspection to determine whether conditions were therefore such that RitIoS had now become appropriate.

(e) Should CS training be mandatory?

I recall - with a shudder! - a couple of reservoirs which, 25 years ago, would have been better defined as 'death traps'. I was also aware that others often took great risks. Later on, therefore, as a member of the Reservoirs Committee (RC), I was fully supportive of the introduction of recommendations regarding CS training for applicants and reapplicants. Certainly, all reservoir engineers should be aware of the principles, definitions, issues and best practices.

( $f$ ) On the other hand, when last reapplying as SupEng, I was pleased that the Institution of Civil Engineers' (ICE) RC accepted that my small portfolio of reservoirs required no CS training and, in conjunction with my undertaking to obtain the appropriate CS training and certification before accepting other reservoirs, recommended my reappointment. The reduced and simplified on-site requirements were reflected in fees continuing to be lower than otherwise necessary to cover the CS training. Further appointments did indeed arise and it was good to be able to spread the significant time and cost of the study, $2 \mathrm{~d}$ training and examination across these reservoirs only.

(g) The numbers of All Reservoirs (AR) engineers are on the decline - the critical issue for the British Dam Society and ICE's RC to address.

AR engineers should preferably be unrestricted so that new and young AR engineers can be fully competent for CSs. However, if a more elderly AR engineer plans to retire rather than reapply though otherwise active and busy, then I consider, on balance, ICE's RC should be flexible here too so that the engineer can continue to keep himself available to exercise his invaluable experience and judgment for five more years.

(h) Meanwhile, small and more sensible nations (is it a coincidence they are also more successful at world cup rugby union?!) are lowering the qualifying capacity to $10000 \mathrm{~m}^{3}$, so a high proportion of reservoirs for first inspection and supervision will be service reservoirs. Undertakers will almost all be potable water suppliers 
and will routinely require evidence before entry, not only of current CS training but also of your National Water Hygiene card administered by Energy and Utility Skills (http://www.eusr.co.uk); your first client should be able to provide the training, test and the UK-wide recognised ID card.

(i) Opportunities for internal inspections of service reservoirs are highly likely to coincide with planned drain-downs for maintenance and remedial work, so contractors will require the same evidence before granting entry.

(j) Undertakers for reservoirs of all types, sizes and numbers are entitled to a choice of qualified engineers, not only geographically well distributed across Britain but, crucially, with suitable capabilities and competencies at proportionate and affordable rates.

I look forward to a further discussion on these important inter-related issues.

\section{Author's reply}

Incidentally, this paper was written several years ago (Hughes, 2014) when I took a doctor and an occupational therapist on a statutory inspection, at the invitation of the RC of the ICE due to worries about whether the RC could, or more importantly should, comment on a candidate's health and physical capabilities. The decision was made; it had to be the responsibility of the individual to be totally professional and to carry out this assessment himself. The need to publish this information became necessary when I observed that a number of panel engineers (both inspecting engineer (IE) and supervising engineer (SE)) were not capable of carrying out their role.

Turning to $\mathrm{Mr}$ Owen's comments as being representative of those who attended the SE Forum I threw out a challenge to all of the water companies to unite to bring some consistency into the issue of access into shafts, tunnels, conduits and chambers as I have been witnessing different standards and conditions across the companies and some changes, such as removal of platforms in shafts, which I believe, are retrograde steps. Thus, while Mr Owen states there is a legal definition there is certainly no consistency in the application of that definition. We must, in my opinion, consider the hazards and reaction in an appropriate and proportionate way to those hazards and the risks posed.

How many times have we found it difficult to carry out our role when we have harnesses, torches, gas detectors, and 10 min sets slung round our necks - when there are vertical ladders with no hoops, and no landings, and we have to slide a block of an arrester system with one hand off the ladder. I certainly would not agree that every space we enter is a CS or should be treated as such. Each one is unique but many can be grouped into different types; however even then you have to consider the entry and exit conditions and the actual layout of ladders/landings and so on.

With regard to any owner, the act states that the owner shall furnish the panel engineer (IE or SE) with 'all reasonable facilities' to enable him to carry out his duties. This could apply to him being required to supply all safety equipment, or paying for the panel engineer to supply them. What is clear is that all activities must be properly assessed and carried out safely. Similarly, the inspection/examination must be carried out fully and all elements must be inspected/ examined.

Certainly, if a space is suddenly assessed as a prohibited area for some reason then the situation would have to be reviewed; perhaps additional facilities (forced or ventilation/ ladders etc.) should be installed and the space inspected/ examined.

In my opinion, the status of us as panel engineers is too low and this is not reflected in the fee rates we charge. Certainly, I do not agree that we should reduce fees according to whether there are CSs at a site or not!

The number of AR engineers is declining - when I joined the panel 30 years ago there were 100 of them, now we are approaching 30, but I do not think this situation is as critical as the SE panel. Back in 1987 there were nearly 500 of them with an average age of 50 years. There are a number of young AR engineers coming forward - what we are not doing is training and enthusing the young to be SEs. I would agree that the RC needs to look into their criteria for appointment and reappointment. As a result too many new candidates are being turned down and discouraged and a number of candidates for reappointment are also being rejected for dubious reasons. I also understand there is a move to require SEs to have at least incorporated engineer status - in my opinion another retrograde step. Previously, the committee had agreed to those who had come through the reservoirs' keeper/headworks role and who had then worked towards a civil engineering qualification and membership of the ICE at any level.

The situation with service reservoirs is potentially full of problems, as Mr Williams states, but even here we need to be sensible. The tanks have usually been empty for several days, all hatches are open, and numerous staff members are in attendance for cleaning down and routine maintenance work.

Training of all types - whether to be able to apply to, and subsequently join the panel, CS training, national water hygiene card training, continued professional development and so on costs money. 
I do not accept that an owner is 'entitled' to proportionate and affordable rates. What we charge now is the lowest level of charge and many charge far too low for the responsibilities undertaken, especially SEs. I personally believe that panel engineers should be respected for their capabilities and competencies and should command fees in line with those skills just like a doctor, accountant or solicitor!

I am sure the debate on these critical issues will continue but I am encouraged by the fact that the big water companies are starting to talk about CSs and we should in due course get some consistency across the various companies with regard to definition, requirements for training, equipment required and facilities provided to gain safe entry and exit and traverse within these spaces while carrying out adequate inspection and examinations.

In point $(h) \mathrm{Mr}$ Williams refers to the ownership of small raised reservoirs and is wrong when he states that 'undertakers will almost all be potable water suppliers'. Currently only $26 \%$ of large raised reservoirs are owned by water companies.

\section{REFERENCE}

Hughes A (2014) Physical capabilities of reservoir panel engineers. Dams and Reservoirs 24(3): 98, http://dx.doi.org/ 10.1680/jdare.15.00003. 